\title{
Teacher Educators' Perceptions of Environmental Education As a Crosscutting Issue and Their Participation in Its Teaching at Kitwe and Mansa Colleges of Education
}

\author{
by \\ Lukonde Derrick Chileshe
}

\section{ABSTRACT}

This study was undertaken to investigate the respondents' perceptions of Environmental Education (EE) and participation in its teaching at Kitwe and Mansa Colleges of Education in Zambia. The study used both qualitative and quantitative research approaches which also included questionnaires, observations and focus group discussions as research instruments. Content analysis was used to ascertain teacher educators' participation in EE. A sample comprised thirty-three purposively selected college teacher educators. The data collected was analysed both qualitatively and quantitatively.

The findings revealed that respondents' views of EE were associated with creation of awareness about the environment and narrowly viewed EE in terms of nature conservation. The majority $(73 \%)$ of the respondents stated that EE was wrongly included in the curriculum. The study further revealed that EE was only taught as topics or subtopics in Science Education (SE), Social, Spiritual and Moral Education (SSME) and Technology Studies (TS) and not as a crosscutting discipline across the curriculum; and that teacher educators essentially adopted teacher-centred methods in teaching EE, concentrating on imparting book-based knowledge. Moreover, no mechanism existed to compel them to integrate EE in lessons taught making the crosscutting approach ineffective in implementing it.

The majority of the respondents had neither received pre-service nor in-service training in EE and if they had received such training, it was irrelevant to the work they were doing. The study concluded that EE should not end at the creation of awareness about the environment but should be linked to knowledge, skills and attitudes required to demand for an action for the environment. The recommendations made were that the curriculum should be reviewed and EE topics or content also be incorporated in all study areas. In addition, the Ministry of Education (MoE) through Teacher Education and Specialised Services (TESS) should formulate a policy framework to guide EE teaching in Primary Colleges of Education. In fact, the EE should formulate or contribute questions toward final examinations and the Ministry of Education (MoE) should procure EE teaching resources. Additionally, teacher educators should use extra curricular activities as learning space for EE.

Lastly, colleges should appoint EE Coordinators to spearhead the EE implementation. There is an urgent need to train or reorient teacher educators in the two colleges on how they could strengthen the grounding in EE. When such training is concluded well, it should now cover all the Zambian Colleges of Education. 


\section{INTRODUCTION}

Zambia's wealth of natural and cultural resources is in danger of widespread depletion and degradation (ECZ, 2000). To alleviate the environmental degradation and create awareness about it in the country, Environmental Education (EE) as a subject or course has been introduced in the formal education programme. Today, teacher education includes EE in its curricular. In Zambia, teacher education institutions are referred to as colleges of education and are responsible for training teachers who teach EE in primary and secondary schools.

The curriculum for Zambian Primary Colleges of Education comprises seven study areas namely, Education Studies (ES), Literacy and Language Education (LLE), Mathematics Education (ME), Science Education (SE), Social, Spiritual and Moral Education (SSME), Expressive Arts (EA) and Technology Studies (TS) all having specific topics, content and outcomes outlined in the syllabi. At the end of each academic year, examinations are prepared based on the above stated topics and content. One of the crosscutting issues included in the college curriculum is the EE. A crosscutting issue is a theme that overlaps between and among the study areas, and is taught in all study areas by all teacher educators (CDC, 2000). The EE is supposed to be taught as a crosscutting issue across the curriculum and all teacher educators in primary colleges of education are by policy, expected to include it in their curricular. However, the EE as a crosscutting issue has no specific content in the syllabi or guidelines that can assist teacher educators to include it in their curricular. This, constitutes a problem because the EE is interpreted and implemented differently by the teacher educators.

The study aimed to explore and evaluate teacher educators' perceptions of EE as a crosscutting issue and participation in its teaching at Kitwe and Mansa Colleges of Education. The following research questions guided the study:

1. What are the views of teacher educators on the teaching of EE as a crosscutting issue in the two colleges of education?

2. How do teacher educators teach $\mathrm{EE}$ as a crosscutting issue in the two colleges of education?

3. How effective is the crosscutting issue approach used by teacher educators in teaching Environmental Education (EE) in the two colleges of education?

4. What are the training needs of teacher educators in the two colleges of education in EE?

\section{METHODOLOGY}

The researcher used both qualitative and quantitative approaches and employed a case study research design. The study population comprised all teacher educators who were actively teaching in the second term of 2010 at Kitwe and Mansa Colleges of Education. Kitwe College of Education was offering the Primary Teachers' Certificate while Mansa College of Education was offering the newly introduced Primary Teachers' Diploma. The sample comprised thirty-three respondents (13 Heads of Section and 20 Senior Lecturers). Both colleges and respondents were purposively selected. The colleges 
were selected on the basis of the high environmental degradation experiences in the provinces in which they were situated (ECZ, 2000). The respondents were selected on the basis of their positions, experience and contributory subjects taught within the study areas. Questionnaires, a structured observation guide, Focus Group Discussion (FGD) guide and content analysis were used to generate data for the study. Research instruments were piloted to ascertain their reliability and validity before they were used in the study.

The questionnaires were used to collect data on; views and challenges encountered in teaching EE, the degree of participation of college teacher educators and their training needs in EE. The Structured Observation Guide was used to determine whether what the respondents claimed in the questionnaires on teaching EE matched with their actual classroom practice. The Focus Group Discussion (FGD) guide was used to collect and clarify views of college teacher educators and effectiveness of teaching EE as a crosscutting issue in the two colleges. The focus of Content Analysis was on whether or not environmental issues were planned for in the study areas; and identify the methods used in EE. The documents that were analysed included the syllabi, college teacher educators' teaching files and students' notebooks. The teaching files comprised; schemes of work, records of work and lecture plans or notes. These documents acted as evidence to the college teacher educators' participation in teaching EE.

Data analysis commenced in the field during lesson observations and focus group discussions. Qualitative data was analysed using the thematic approach and a threestep process was employed; data reduction, data display and drawing conclusions or verifications. Quantitative data was analysed using SPSS computer software. Quantitative data focused on the extent of college teacher educators' participation in teaching EE and their training needs.

\section{FINDINGS}

The findings are organised according to the four research questions.

\section{The Views of Teacher Educators on the Teaching of Environmental Eduction (EE) as a Crosscutting Issue}

The majority of the respondents ( $82 \%$ ) considered EE as creation of awareness about the environment in terms of ecological conservation. The EE was also perceived by teacher educators as being both a main and extra-curricular activity. As a main curricular activity, EE was a topic taught in Science Education (SE), Social Spiritual and Moral Education (SSME) and Technology Studies (TS). However, the majority of the respondents (73\%) claimed that $\mathrm{EE}$ as a crosscutting issue was wrongly included in the curriculum although all respondents stated that it was a necessity. The respondents claimed further that EE only existed in the two colleges as a policy as it was silent and just only taught in passing. 


\section{Teacher Educators' Participation in Teaching EE as a Crosscutting Issue}

In all the lessons that respondents presented and observed by the researcher, opportunities to integrate environmental issues existed but none of the respondents integrated EE in them. EE was only taught in SE, SSME and TS study areas as independent topics. However, respondents teaching Industrial Arts within TS study area did not teach EE as they claimed that the syllabus did not have EE related topics. In general, the participation of respondents in teaching EE in the two institutions is shown in Figure 1.0 which reveals that there was a slight difference between respondents who taught EE (about $39.4 \%$ ) and those who didn't (42.4\%). Moreover, it indicates that a significant number of respondents were not certain about their involvement in teaching EE. Of the respondents who claimed to teach EE, the majority of them $(77 \%)$ indicated that teaching EE was not a priority that it was only taught when it appeared as a topic in schemes of work. The majority (69\%) of the respondents teaching Environment Education (EE) concentrated on imparting knowledge to the students while the rest $(31 \%)$ concentrated on teaching content and methodology. The taught content constituted the knowledge about the environment while methodology focused on the pedagogy of EE.

Figure 1.0: Distribution of Respondents by whether they Teach EE

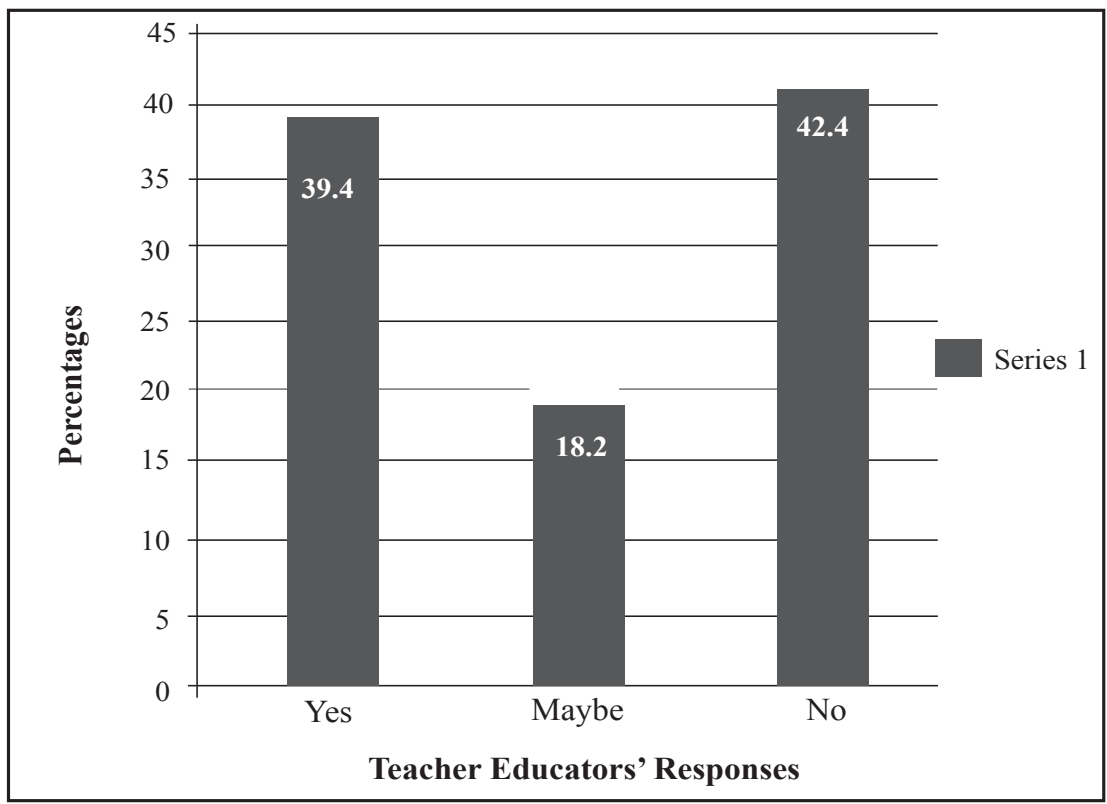

Source: Field Data, 2012

Additionally, teacher educators dominated their lessons by talking for a longer time than students. It was observed that when teaching environmental issues, respondents were more concerned with teaching book-based knowledge than applying the knowledge. Close examination of the teaching files, indicated that no EE was taught in (ES), (LLE), ME and (EA) study areas. However, students 
had EE theory components written in their SE (SSME) and Technology Studies (TS) notebooks but there was no indication of practical work or field work being recorded. Nonetheless, all study areas had incorporated HIV and AIDS as a social component of EE. However, five methods were used to teach EE by the respondents and the frequency of using them are shown in Table 1.0.

Table 1: Methods Used in Teaching EE

\begin{tabular}{|l|c|c|}
\hline Methods used in teaching EE & Frequency & Percentage (\%) \\
\hline Demonstration & 1 & 3.3 \\
Discussion & 4 & 20 \\
Lecture & 8 & 26.7 \\
Role play & 1 & 3.3 \\
Question and answer & 12 & 36.7 \\
Field trips (Nature walks) & 2 & 6.7 \\
Project & 1 & 3.3 \\
\hline Total & $\mathbf{3 0}$ & $\mathbf{1 0 0}$ \\
\hline
\end{tabular}

Source: Field Data, 2012

The results in Table 1 further indicate that Environmental Education (EE) was frequently taught using a teacher-centred approach which did not promote active learner participation.

EE activities also took place outside the classrooms where the majority of the respondents $(64 \%)$ claimed that they participated in these activities. Table 2.0 below shows the type of EE activities respondents participated in outside the classroom in the two institutions.

Table 2: Activities Outside the Classroom in which Respondents Participate

\begin{tabular}{|l|c|c|}
\hline Types of activities & Frequency (n) & Percentage (\%) \\
\hline Clubs & 3 & 11 \\
Preventive Maintenance Systems (PMS) & 19 & 68 \\
Environmental day commemoration & 2 & 7 \\
Production Unit (PU) & 4 & 14 \\
\hline Total & $\mathbf{2 8}^{*}$ & $\mathbf{1 0 0}$ \\
\hline
\end{tabular}

*Note $n>21$, respondents were involved in more than one activity

The majority of the respondents participated in supervising students in Preventive Maintenance Systems (PMS). Nonetheless, a few respondents also participated in clubs, environmental day commemoration and production unit activities. 


\section{Effectiveness of the Crosscutting Issue Approach Used in Teaching EE in the Two Colleges of Education}

Only 39.4 per cent of the thirty-three teacher educators interviewed taught EE in their lessons and taught when it appeared as content in certain topics of the schemes of work. In short, EE as a crosscutting issue was not effectively implemented by the respondents in the two colleges as demanded by the curriculum. The majority of the respondents $(70 \%)$ indicated that there was no mechanism to compel them to teach $\mathrm{EE}$ as a crosscutting issue was taught. However, 30 per cent of the respondents stated that the presence of topics in the syllabus and schemes of work was a mechanism that was employed to ensure that teacher educators taught EE.

The following are the other reasons that led to the failure by the respondents to teach $\mathrm{EE}$ as a crosscutting issue in their lessons:

\section{(a) Curriculum was Unclear}

Through Focus Group Discussions (FGDs) the respondents identified the existing curriculum as the first barrier to effective teaching Environmental Education (EE) in the two colleges. The challenges related to the curriculum were:

(i) The syllabi did not specify topics and content to teach under Environmental Education (EE). In short, the syllabi did not contain EE topics except in (SE), (SSME) and Technology Studies (TS) study areas. For example, 'It all begins with the curriculum itself which is not clear. There is nothing apart from the statement that crosscutting issues in this case, environment, should be taught in every study area. So, how does one tell what and when to teach it? In short, the curriculum is not clear on how we need to include EE'. Another issue brought out was that some topics in the syllabi were unrelated to EE which made it difficult to integrate EE in to those topics.

(ii) The syllabi or teacher education curriculums were overloaded. For example:

\footnotetext{
'The current syllabi were so overloaded that there was no room for more work. Even if I was trained and had the necessary knowledge and skills to integrate it, and reference books are available, still it will not be possible to teach EE. If we fail to complete teaching the work in the current syllabus, how possible is it that we can dare to include in more work and finish teaching it?'
}

(iii) The curriculum was examination-driven. Respondents claimed that they primarily prepared students to pass examinations. They questioned the wisdom teaching EE to someone that was not included in the 
students' final examinations. For example, 'Teaching EE consumes time to complete the outlined content in the syllabus'. Another issue raised on the examination was the actual setting of questions. Respondents said:

\footnotetext{
'When setting examination questions for the examination EE has no standard reference point ... content to base the questions on, how do you know what was covered or left out as it is left to individual lecturer's discretion whether to teach it or not?'
}

Respondents felt it was difficult to set fair questions for all students because different topics were covered.

\section{(b) Lack of Guidelines on Teaching EE}

There were a number of insights from the discussions that confirmed that there was lack of guidelines in teaching of EE. For example, a respondent explained that 'There are no guidelines to encourage teaching EE in all study areas in the college. So, I cannot say it is a priority to me but a burden. I do not teach it when I am supposed to' or 'a mere statement that Environmental Education (EE) should be taught as a crosscutting issue in all study areas is not helpful'.

\section{(c) Lack of Knowledge and Skills by Respondents}

It was evident from the respondents that they lacked knowledge and skills to effectively implement EE in their lessons. For example, 'Without the knowledge about EE, I would not want to show my ignorance to students' or 'If somebody is asking about knowledge and skills of teaching EE, I confess I am surely incompetent in this area'.

\section{(d) Negative Attitude of Respondents}

There were many elements of the discussion that revealed that negative attitude of respondents was a challenge to the inclusion of $\mathrm{EE}$ in lessons in the two colleges. Implicitly, respondents seemed unwilling to teach EE although all of them accepted that it was an important component of teacher education curriculum. Respondents were quoted as saying, 'Why should we not leave EE to specialists like Science Education (SE) and Social Spiritual and Moral Education (SSME)? 'We are not specialists' or 'I was not trained to teach other things apart from my area of specialisation'.

\section{(e) Lack of ownership}

It was particularly evident that respondents from Education Studies (ES), Literacy and Language Education (LLE), Mathematics Education (ME) and Expressive Arts (EA) study areas who had no environmental topics or related 
topics in their syllabus were not eager to integrate EE in their study area. They felt EE was not their concern. For example:

'Have you ever heard about the tragedy of the commons? If no one owns something there is no care for it so is the case with EE. So long as EE was a common issue college teacher educators expected the other study areas to teach it and in the end it dies out and remains only in study areas where it comes as topics' or 'The perception among teacher educators was that the experts of EE are Science teacher educators. They were the people who were competent to articulate the issues in EE, so much that it was even included in the syllabus for them'.

\section{(f) Lack of Resources}

Lack of, and inadequate resources in terms of funds, support, and teaching/ learning materials was stated as challenges to teaching EE in the two colleges. According to respondents, without resources it was very difficult to teach EE. For example, 'When you look at the concept itself, it was an emerging concept which did not have enough teaching. For us who are teaching it, we find it difficult to get the reference materials. Last time I was teaching on Education for Sustainable Development and there was no single book referring to it in the college' or '... It is also difficult to organise field trips due to lack of resources and big number of students available'.

\section{(g) Training needs of College Teachers Educators in EE}

More than half (55\%) of the respondents did not have Environmental Education (EE) component in their pre-service teacher training. The majority of respondents $(61 \%)$ who claimed to have had training in EE indicated that their knowledge was inadequate to effectively teach EE in colleges. Only 33 per cent of the respondents had attended in-service training in EE and competencies gained from these trainings included: how to teach EE, knowledge about EE, community partnership, localising the curriculum, material production and management of PMS. All respondents indicated that they needed to undergo training in EE and the training needs that emerged are featured in Table 2 below.

\section{Table 2: EE Areas for Training Respondents}

\begin{tabular}{|l|c|c|}
\hline \multicolumn{1}{|c|}{ Theme } & Frequency (n) & Percentage \% \\
\hline Content in EE & 5 & 11 \\
Methodology in EE & 3 & 7 \\
Content and methodology & 11 & 24 \\
Material production & 1 & 2 \\
All components of EE & 26 & 56 \\
\hline Total & $\mathbf{4 6}^{*}$ & $\mathbf{1 0 0}$ \\
\hline
\end{tabular}

*Note $n>33$, as some respondents gave two or more responses

Source: Field Data, 2012 
Overall, 56 per cent of the responses indicated that training was needed in all aspects of EE while 24 per cent of the responses suggested that training was needed in both content and methodology. Responses on content only accounted for 11 per cent of the total responses. Out of the 46 responses, 7 per cent stated methodology as the specific area for training. Lastly, 2 percent of the total responses suggested material production as training needs.

\section{Discussion of Findings}

The majority of the respondents located their description of Environmental Education (EE) in one of the three Tbilisi Conference EE Goals, that of creation of awareness about the environment. It is important to note that environmental awareness is a limited term, which means having knowledge about the environment; it is used interchangeably with EE (ECZ, 2000). However, EE is a broader term which encompasses awareness, knowledge, attitudes, values and participation. It should not be seen merely as a strategy for creating awareness of the environment, but also as a means towards developing positive concern for maintaining the quality of life of the people on earth (Le Roux, 2001; UNESCO, 1985). Since EE was viewed as the creation of awareness or acquisition of knowledge about the environment, even the way it was taught reflected merely imparting knowledge into students. Teachers' pedagogical practices are related to their views (Hart, 2003). Moreover, teachers' conception about a subject also influences their instructional planning and their delivery of the subject matter (Mosothwane, 2000). The respondents' idea that EE is the creation of awareness about the environment, implied that they considered EE as education about the environment. However, a few of the respondents rightly viewed it as education in and for the environment. This situation was understandable as EE was a new field in Zambia (Namafe, 2005). However, there was need for it to be viewed by all as education in and for the environment.

It was evident that respondents perceived $\mathrm{EE}$ in terms of natural or ecological conservation. This perception lacks the view of the environment in totality as outlined in the principles of EE. The EE should consider the environment in its totality (Le Roux, 2001; Rao \& Reddy, 1996; UNESCO, 1985). The way a teacher educator perceives the environment restricts his/her participation in its teaching (Sandell et al., 2003). The narrow understanding of EE in terms of the natural or ecological aspect could be the reason why it was perceived to be scientifically oriented and associated with Science Education (SE). Therefore, the narrow perception of EE calls for a broadened scope as implied in the Tbilisi Declaration.

In Science Education (SE), Social, Spiritual and Moral Education (SSME) and Technology Studies (TS) study areas, EE was not treated as a crosscutting issue but as independent topic. The perception that EE was 'wrongly included' as a crosscutting issue in the curriculum implies that it was not convincing that it should be taught in all study areas. The Environmental Education (EE) was latently viewed as a separate subject or a special topic (Jones, 1996). However, the inclusion of the EE as a cross-cutting issue 
in the curriculum was appropriate. In fact EE should not to be added to educational programmes as a separate discipline or subject for study but as a dimension to be integrated into them (UNESCO, 1985; Pandya, 2000).

The findings further indicated that 'action for the environment' was not an area of focus by those teaching EE in the two colleges. The finding generally agrees with the Jones' (1996) findings that the action component of EE is often missing from teacher education programmes. This ties in well with most respondents' view that EE was about creating awareness about the environment while information plays an important role in creating a climate of awareness, it cannot in itself, offer a solution to the problem (UNESCO, 1980). The EE should not only create awareness but also provide new patterns of behaviour in response to the environment (UNESCO, 1980; Le Roux, 2001, Beckford, 2008 and Fien, n.d).

The teaching methods frequently used in teaching EE were in the form of question/ answer and lecture. These two methods promoted a teacher-centred approach to teaching. The frequent use of question/answer and lecture methods ties in well with the Ministry of Education (MoE) (1996) view that teacher training was promoted rigid teacher-centred methodologies. The methods used in teaching EE also describe the form of EE practised in the two mentioned colleges of education. It was evident that the three forms of EE were practised in the two colleges, although there was more education about and less in and for the environment.

Respondents participated in Preventive Maintenance System (PMS), clubs, production units and environmental day commemorations. These activities certainly are important in teaching EE. However, what was interesting about PMS was that the majority of the respondents in the two colleges were only involved in the end product of students' work and not the process of teaching. This has developed a negative attitude among the students who view PMS as a purely manual work activity. Whilst respondents from Technology Studies (TS) taught PMS in their study area, the way it came out was mainly to provide information on what PMS was and who should do it. The EE was used to create awareness and understanding about PMS among students and not necessarily to equip them with attitudes, values and skills required to carry it out. Thus EE should provide opportunities for learners to enhance their capacity for independent thinking and effective responsible action (www.naaee.org).

According to Jones (1996), the development of critical and systems-thinking skills must be components of pre-service Environmental Education (EE) training because the skills are necessary for students to understand the complex relationship existing between humans and the environment, and to be able to critically analyse how their actions would impact the natural world. In addition, EE should enable the learners to have a role in planning their learning experiences and provide an opportunity for decision-making and accepting their consequences (UNESCO, 1985).

During Preventive Maintenance Systems (PMS) students were not given room to engage in the decision-making process but followed orders from supervisors (teacher educators). There is an urgent need for teacher educators to target the attitude skill development dimension in students if PMS is to contribute positively to EE in the 
two colleges. While it was true that PMS was contained in Technology Studies (TS) syllabus and was taught, it clearly fell short of what EE was all about. If PMS was taught to students, why did they continue to have a negative attitude towards it? A possible explanation would be that only giving information about PMS was not enough as it did not allow for the students to act for the environment. However, this cannot be termed as full teacher educators' participation in EE although PMS was an excellent learning activity for EE.

It is worth noting that while the club members students, out of their own initiatives, were actively engaged in EE through cleaning of the college clinic or solid waste management, dancing and singing, respondents did not teach these activities. In this view, it is quite difficult to say EE was taught through clubs but the presence of it in the two colleges can be attested by the presence of the clubs and related activities. According to MTENR (2007), one strategy of enhancing EE and public awareness is through establishment of clubs. Through clubs, individuals got involved in active problem-solving processes within the context of specific realities, relating what is learnt in the classroom to community action (UNESCO, 1985).

The lack of a mechanism to compel respondents to teach EE as a crosscutting issue meant that its teaching was optional. Presently, teaching EE is done through individual effort of one or two committed teachers (Jones, 1996, Powers, 2004, Beckford, 2008, Gough, 2009). Respondents from Science Education (SE), Social Spiritual and Moral Education (SSME) and Technology Studies (TS) study areas were only able to teach Environmental Education (EE) when it appeared as an independent topic in the syllabi. This finding agrees with Jones (1996) that although EE does exist in teacher training programmes, it is more of a policy than a practice. The policy of teaching EE as a crosscutting issue was not effective because lit was only taught when environmental topics appeared in the schemes of work from the syllabi. There was no consistency in the teaching of EE by the respondents. Gough (2009) observed that despite many efforts, there was a recurring testimony to lack of success in introducing coherent or consistent programmes of EE in teacher education.

The findings revealed that only 33 per cent of the respondents had received inservice training in EE and the competencies gained by the respondents from training fell under conceptual environmental awareness competency. In view of this, it could be concluded that the in-service training in EE was ineffective as the competencies gained from it did not explicitly cover all areas of EE and did not influence holistic EE in the respondents' classroom practice. Without proper training, it becomes almost impossible to effectively implement a programme which requires expertise. The unanimous response by respondents that they needed to undergo training implied that they lacked the necessary competencies to effectively implement EE. Clearly, qualified EE teachers act as stimuli to the introduction of EE into the school curriculum (Jones, 1996).

The majority (56\%) of the participants claimed that they needed training in all areas of EE. It is worth noting that, while some respondents picked content, methodology and material production as specific areas for training, these areas on their own are 
inadequate. The question that needs to be answered is, what specific competencies does an environmental educator require in order to effectively instil EE in the learners? The foundational competencies required by effective environmental educators are broadly categorised into professional education and EE content (Agrawal \& Aggarwal, 1997; Rao \& Reddy, 1996; UNESCO, 1987; Sytnik et al., 1985). The competencies in EE content comprise ecological foundations, conceptual environmental awareness, environmental issue investigation and evaluation, and environmental action skills.

\section{CONCLUSION}

It was evident that a gap existed between the Ministry of Education's policy of teaching $\mathrm{EE}$ as a crosscutting issue and implementation of it in the classroom. Respondents perceived EE as the creation of awareness about the environment and that it was wrongly included in the curriculum. The teacher educators lacked the required knowledge and skills needed to interpret and integrate EE in their lessons. Moreover, the curriculum was not explicit effectively integrate EE into it. Most of the respondents had neither pre-service nor in-service training in EE and if they did receive such training then it was irrelevant to what they were supposed to do.

Therefore, it is recommended that the curriculum be reviewed and EE topics/ content incorporated in all study areas. Moreover, the Ministry of Education (MoE) through Teacher Education and Specialised Services (TESS) should formulate a policy framework to guide EE teaching in Primary Colleges of Education. In addition, EE should formulate or contribute questions in final examinations and MoE should procure EE teaching resources. Respondents should use extra curricular activities as learning space for EE. Lastly, colleges should appoint EE coordinators to spearhead and re-orientation of teacher educators in EE implementation.

\section{REFERENCES}

Agrawal, S.P. and Aggrarwal, J.C. (1996), Environmental Protection, Education and Development: A reference manual. New Delhi: New Concepts.

Beckford, C. (2008), 'Re-Orienting Environmental Education in Teacher Education Programmes in Ontario', Journal of Teaching and Learning, vol. 5, No. 1.

Curriculum Development Centre (2000), Environmental Education Teacher's Manual. Lusaka: CDC.

Environmental Council of Zambia (2000), State of the Environment. Lusaka: Horizon Printer.

European Commission (2009), Environmental Education in the Educational Systems of the European Union Synthesis Report. Frankfurt: European Commission, www. citeseerxist.psu.edu.org accessed on 7 July 2010.

Fien, J. (1993), For the Environment: Critical Curriculum Theorising and Environmental. Geelong: Deakin University.

Fien, J. (n.d.) Module 2 - A Whole School Approach, UNEP, ACEID www.awholeschoolapproach.org (accessed 10 July 2010). 
Gough, A. (2009), Not for Want of Trying: Strategies for Reorienting Teacher Education for ESD, www.esdteachereducation.org (accessed 20 August 2010).

Hart, P. (2003), Teachers Thinking in Environmental Education: Consciousness and Responsibility. New York: Peter Lang.

Jones, A.W. (1996), Teach Our Teachers Well: Strategies to Integrating Environmental Education into Teacher Education Programme, www.teachourteacherswell.org (accessed 7 July 2010).

Le Roux, K. (2001), Environmental Education Processes: Active learning in School. Pietermaritzburg: University of Natal Press.

Ministry of Education (1996), Educating our Future, National Policy on Education. Lusaka: Zambia Educational Publishing House.

Ministry of Tourismn (2007), Environment and Natural Resources: National Environmental Policy, MTENR, Lusaka.

Mosothwane, M. (2000), 'Pre-service Teachers' Conception of Environmental Education, Research in Education No. 68.

Namafe, C.M. (2005), Integrated Development Environmental Issues: Proposed Improvement to the Zambian Basic School Geography (Grade 8 -9). Lusaka: New Horizon Printing Press.

Pandya, M. (2000), Teacher Education for Environmental Education in India, http:// www.fsifee.u-gakugei.ac.jp (accessed on 05/08/2010).

Powers, A. L. (2004), Teacher Preparation for Environmental Education: Faculty Perspectives on the Infusion of Environmental Education into Pre-Service Methods Courses, in the Journal of Environmental Education, Vol. 35, No. 3, www.peerassociate.net (accessed 7 July 2010).

UNESCO (1980), Environmental Education in the Light of the Tbilisi Conference: UNESCO.

UNESCO (1985), Environmental Education Module for In-service Training of Science Teachers and Supervisors for Secondary School: Environmental Education Series 7: UNESCO.

Rao, V.K. and Reddy, R.S. (1996), Environmental Education. New Delhi: Commonwealth Publishers.

Sandell, K., Ohman, J. and Ostman, L. (2003), Education for Sustainable Development; Nature, School and Democracy. Lund: Studentlitteratur.

Sytnik, K.M., Cherednichenko, L.S., Sakhaev, V.G., Lebedinsky, Yu and Kolybin, V.A. (1985), Living in the Environment: A Resource Book for Environmental Education. Kiev: UNESCO-UNEP.

www.naaee.org, Asia-Pacific Environmental Innovation Strategies; Research on innovation and strategy policy options (accessed 23 October 2010).

Zamm, M. (2005), Teacher Preparation and Environmental Education: Meeting the Challenge in New York State, www.zammmike.nysed.gov (accessed 5 February 2010). 